\title{
NÍVEL DE APRENDIZAGEM DO ESTUDANTE DE CONTABILIDADE Um modelo de diagnóstico a partir da Taxonomia Revisada de Bloom
}

\author{
LEVEL OF LEARNING IN STUDENT ACCOUNTING \\ A diagnostic model from the Revised Bloom's Taxonomy \\ Raimundo Nonato Lima Filho \\ rnfilho@uneb.br \\ Universidade do Estado da Bahia \\ Débora Aline Nascimento de Jesus \\ deboraalinenj@yahoo.com.br \\ Universidade do Estado da Bahia
}

\section{RESUMO}

Este estudo objetivou analisar o nível de aprendizagem dos discentes, através do semestre em que se encontram no curso de Ciências Contábeis, nas modalidades de ensino à distância (EAD) e presencial utilizando os pressupostos da Taxonomia Revisada de Bloom. Para que o objetivo fosse cumprido foi realizada uma pesquisa descritiva e quantitativa com 233 graduandos de Instituições de Ensino Superior localizadas nos municípios de Euclides da Cunha e Senhor do Bonfim - Bahia, Brasil. Como instrumento de coleta de dados foi utilizado um questionário com um bloco composto por questões estruturadas, baseadas em uma hierarquia propostas pela Taxonomia Revisada de Bloom. Os resultados indicaram que há diferença significativa no nível da aprendizagem entre os discentes mediante o semestre em que se encontram no curso, tanto na modalidade presencial quanto na $\mathrm{EAD}$, sendo que na modalidade presencial o ascender do nível de aprendizagem foi mais significativo, já em relação ao nível de aprendizado com a variável "idade" verificou que os alunos mais maduros possuem um maior nível de aprendizagem, corroborando assim com evidências empíricas de outras pesquisas relacionadas com esta temática. Esta pesquisa contribui para uma melhor concepção sobre o nível de aprendizagem dos discentes analisados a partir do diagnóstico da Taxonomia Revisada de Bloom.

\section{Palavras-chave: Nível de Aprendizagem, Taxonomia Revisada de Bloom, Modalidades de Ensino, Contabilidade.}

\begin{abstract}
This study aimed to analyze the learning level of students through the semester in which they find themselves, in the course of Accounting in the forms of distance learning (ODL) and presence using the assumptions of Bloom's Taxonomy Revised. For the purpose was fulfilled was performed a descriptive and quantitative with 233 graduates of Higher Education Institutions located in the municipalities of Euclides da Cunha and Senhor do Bonfim - Bahia, Brazil. As data collection instrument used was a questionnaire with a block composed of structured questions, based on a hierarchy proposed by the Revised Bloom's Taxonomy. The results indicated a significant difference in the level of learning among students through the semester in which they are in the course, both in the classroom and in distance education, and in the classroom the learning level rise was more significant, as compared the level of learning with the variable "age" found that more mature students have a higher level of learning, thus corroborating with empirical evidence from other research related to this issue. This research contributes to a better design on the learning level of students analyzed from diagnosis of Bloom's Taxonomy Revised.
\end{abstract}

R. Cont. Ufba, Salvador-Ba, v. 7, n. 3, p. 38 - 58, dezembro-março 2014 
Keywords: Level of Learning, Revised Bloom's Taxonomy, Methods of Teaching, Accounting.

Artigo recebido em: 25.11.2013; Aceito em: 15.02.2014

\section{Introdução}

A principal característica dos cursos oferecidos por Instituições de Ensino Superior (IES) é a de formar os futuros profissionais que atuarão no mercado de trabalho com competência, profissionalismo e credibilidade, além disso, providos de desenvolvimento intelectual diante da sociedade (ANDRADE, 2002). Por conta disso, um dos fatores essenciais para especificar a qualidade da aprendizagem dos alunos, na educação superior é estar apto a inserir-se profissionalmente no mercado de trabalho. Portanto, espera-se que o egresso de uma IES proporcione os requisitos mínimos para o exercício profissional e as capacidades intelectuais e emocionais essenciais para dar prosseguimento ao aprendizado por toda a sua vida. Mas, para que isso aconteça o processo de ensino tem que alcançar determinados objetivos.

Na perspectiva docente é relevante adotar uma organização em uma estratégia sequencial e lógica, mediante suas metodologias de ensino. Pois, o processo de aprendizagem, normalmente, é um retorno do indivíduo ao estímulo em que foi submetido diante de uma situação-problema. O desenvolvimento do conhecimento poderá ser possível mediante a conexão de uma interação recíproca e interdependente entre o discente e o elemento a ser aprendido.

Para alcançar sua finalidade e oferecer suporte para que os alunos consigam subsídios para desenvolver suas próprias habilidades, competências e valores para gerarem capacitação pessoal e profissional, transformando-os em agentes de mudanças e participantes plenos na sociedade em que estão inseridos, torna-se necessário que o professor adote e selecione primeiramente seus objetivos pretendidos quanto à aprendizagem conforme suas prioridades e a sua viabilidade de cumprimento esperando também uma resposta positiva mediante, sobretudo, à vontade e desempenho do discente.

Diante deste contexto, uma das ferramentas existentes capaz de facilitar esse processo nos cursos superiores é a Taxonomia proposta por Bloom et al. (1956), que tem como objetivo auxiliar no planejamento, esquematização e controle dos objetivos de aprendizagem. A teoria da aprendizagem, proposta por Bloom e sua equipe, se divide em três domínios: cognitivo, afetivo e psicomotor. Na conjuntura desta pesquisa, adota-se somente o domínio cognitivo, pois está relacionado ao aprender, dominar um conhecimento, adquirir uma nova informação, para o desenvolvimento intelectual, de habilidade e de atitudes e através desses objetivos afirma-se o que é esperado que os discentes aprendam, além de evidenciar o que são capazes de desempenhar com aquele conhecimento (ESKRIDGE, 2010). Não se utiliza o domínio afetivo, pois enfatizam os sentimentos, a emoção ou a condição de aceitação ou rejeição, tais objetivos são expressos como interesses, atitudes ou valores. Assim como o domínio psicomotor que envolve objetivos que enfatizam alguma habilidade muscular ou motora (VEERAVAGU et al., 2010).

A Taxonomia Revisada de Bloom, reformulada por Anderson e seus colaboradores utiliza como requisito uma classificação hierárquica para os objetivos de aprendizagem, seus níveis se dividem em seis categorias: lembrar, entender, aplicar, analisar, avaliar e criar. Para a ascensão de uma categoria para outra, é necessário ter obtido o desenvolvimento ideal na fase anterior, pois cada uma utiliza de habilidades que foram adquiridas dos níveis antecedentes, dessa forma o ideal é alcançar o último nível, a capacidade de criar (GATZEN; PAPE; RUFFERT, 2007). Com base nessa escala hierárquica pretende-se verificar os níveis de aprendizagem dos 
discentes nas modalidades analisadas, mediante o estágio em que se encontram no curso, ou seja, inicial, intermediário e concluinte. Assim insere-se o seguinte problema de pesquisa: existem diferenças significativas no nível de aprendizagem dos alunos em relação ao estágio em que se encontram no curso de Contabilidade nas modalidades presencial e à distância?

O objetivo geral desta pesquisa é analisar o nível de aprendizagem dos discentes, através do semestre em que se encontram no curso de Contabilidade nas modalidades de ensino EAD e presencial utilizando os pressupostos da Taxonomia Revisada de Bloom. Como objetivo específico, analisar se o desempenho dos alunos investigados é alterado mediante variável idade a partir da aplicação do instrumento próprio de pesquisa, como é demonstrado na Figura 1.

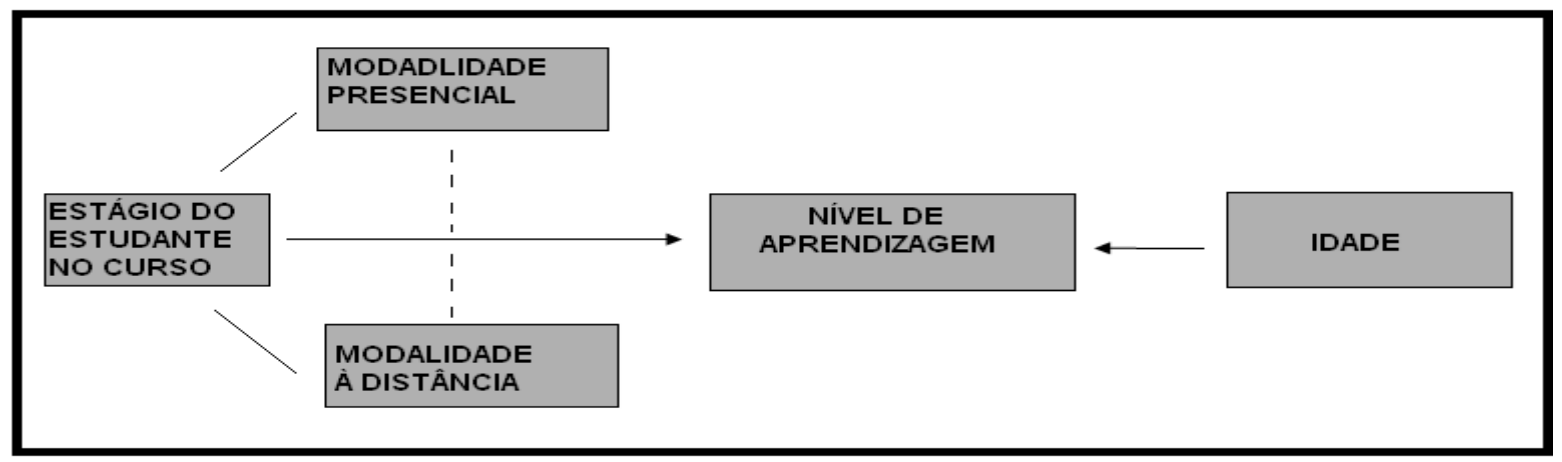

Figura 1 - Modelo de Pesquisa (Objetivos)

Fonte: Elaboração própria, 2013.

Esta pesquisa tem o intuito de proporcionar um retrato da atual conjuntura do ensino presencial e à distância e sua implicação na realidade do ensino contábil, mediante a evolução do estágio do estudante no curso. Portanto, as conclusões desta pesquisa poderão contribuir de forma significativa com informações para os futuros ingressos na área da Contabilidade, bem como identificar o nível de aprendizado nas instituições de ensino analisadas, através da hierarquia da Taxonomia Revisada de Bloom.

$\mathrm{O}$ estudo está organizado em partes inter-relacionadas, iniciando com a introdução. Na sequência, aborda conceitualmente pontos mais relevantes sobre o ensino de Contabilidade no Brasil, o ensino-aprendizagem na Contabilidade e por fim, a conceituação da Taxonomia de Bloom. Em seguida, apresentam-se os procedimentos metodológicos para operacionalizar os objetivos fixados por esta pesquisa, posteriormente concerne à análise dos dados. A partir da adoção de métodos quantitativos, busca-se apresentar a amostra da pesquisa, expor o emprego e execução de todos os procedimentos para o tratamento e análise dos dados e realização dos testes de hipóteses, concluindo com as considerações finais desta pesquisa.

\section{Referencial Teórico}

\subsection{Ensino de Contabilidade no Brasil}

No Brasil, o ensino de Contabilidade iniciou-se a partir das Escolas de Comércio. Essas aulas surgiram no Rio de Janeiro, conforme o Alvará de 15 de julho de 1809, e eram destinadas a ensinar o processo de escrituração, sendo originárias de Portugal e tinha como professor José da Silva Lisboa, conhecido como Visconde de Cairú (PELEIAS et al., 2007). 
Com o passar do tempo, essas aulas foram se adequando e assim extinguiram-se e surgiu o Instituto Comercial do Rio de Janeiro, acrescentando desta forma mais disciplinas, tempo de duração e sendo mais rígidos nos pré-requisitos para a seleção. Nesta mesma época foi criada a Associação dos Guarda-Livros da Corte, reconhecida pelo Decreto Imperial 4.475/1870 e assim o Guarda-Livros foi a primeira função da área de Contabilidade, a qual, se tornou uma das primeiras profissões liberais no Brasil. Nessa mesma ocasião houve também a criação da Academia de Comércio do Rio de Janeiro, dividindo os cursos em dois, um com formação geral o outro de nível superior.

Somente em 1902 foi instituída a Fundação Escola de Comercio Álvares Penteado em São Paulo. Alguns autores preferem fazer recair a honra do pioneirismo na Escola Politécnica da Universidade de São Paulo, a qual, alguns anos antes, em seu Curso Preliminar, já incluía a disciplina Escrituração Mercantil. Conquanto, legalmente e cronologicamente tais autores possam ter razão, porém, o fato de haver a disciplina de Escrituração Mercantil não caracteriza um Curso de Contabilidade (IUDÍCIBUS, 2006 apud PELEIAS et al. 2007).

Durante esses períodos os contadores eram chamados de "guarda-livros", eram responsáveis pelas funções burocráticas, fazia os contratos e rescisões comerciais, realizavam os pagamentos e recebimentos, ou seja, controlavam a entrada e a saída de dinheiro, fazia as correspondências e todas as escriturações contábeis manualmente, motivo pelo qual o profissional deveria ter uma ótima caligrafia, além disso, eles tinham que falar fluentemente o idioma português e francês, existia também a busca da padronização das práticas, que eram focadas na escrita e possuíam pouco envolvimento nos negócios (REIS; SILVA, 2007).

Diante da tamanha evolução dos cursos de Ciências Contábeis, houve a divisão dos profissionais de Contabilidade em 1946. Sendo assim, deixa-se de lado aquele profissional que era exclusivamente ligado a fazer as partidas dobradas e dava maior atenção ao fisco. Surge então o profissional contábil atual o qual está voltado a atender, principalmente devido às inovações tecnológicas, as soluções para os problemas com rapidez, auxiliar os gestores na tomada de decisões, além de manter-se atualizado continuamente.

Verifica-se que o ensino da Contabilidade iniciou no século XIX, com a implantação formal das Aulas de Comércio e do Instituto Comercial do Rio de Janeiro. No século XX, constata-se o surgimento do ensino comercial, com os cursos profissionalizantes na década de 20 , a concepção do ensino superior na década de 40 e o programa de pós-graduação na década de 60 na Faculdade de Economia, Administração e Contabilidade da Universidade de São Paulo (FEA/USP).

Atualmente, o Brasil encontra-se em um período de grande progresso no avanço de matrículas, de mudanças de funções e alterações em sua composição organizacional, a questão do financiamento para instituições públicas, o aumento significativo das tecnologias de informação, evidenciando outras formas de aplicação e abrangência do ensino como na modalidade à distância, além da internacionalização dos currículos da educação superior, não obstante ao Curso de Ciências Contábeis.

\subsection{Ensino - Aprendizagem na Contabilidade}

A aprendizagem se consolida a partir de situações que determinam que o aluno se desenvolva com maior profundidade em um determinado tema, diante de suas inúmeras habilidades racionais, lógicas e emocionais. Ou seja, a aprendizagem, por conseguinte, é o processo cognitivo pelo qual o indivíduo obtém conhecimentos e se torna apto a interagir com o mundo. Logo, o processo de ensino-aprendizagem é apresentado como aquele em que existe o envolvimento do discente, instituição, assunto e docente. De tal modo, tanto os docentes e instituições de ensino, como os discentes, precisam ter como propósito contestar e provar novas 
opções para assim obter uma ampliação da eficácia e da eficiência neste procedimento (SILVA, 2006). Assim como afirma Cornachione Júnior (2004) a partir da combinação especial de recursos e abordagens (ensino), pretende-se que a produção pretendida (aprendizagem) seja atingida com o melhor emprego dos recursos oferecidos.

Diante das exigências do mercado para atender adequadamente aos cidadãos, é pretendido que o profissional esteja totalmente apto. Desse modo, a Contabilidade irá até onde seus profissionais puderem levá-la. Seu reconhecimento, importância e valorização, deverão ser, necessariamente, mediante o conhecimento, as habilidades e atitudes dos profissionais envolvidos (LOPES; PEREIRA; SANTANA JR., 2008).

Já na área contábil, a precisão pelo aperfeiçoamento das capacidades individuais se intensificou com as recentes atualizações na legislação societária brasileira e a convergência das normas de contabilidade (NBC) com as normas internacionais (IFRS). Estas mudanças incentivaram e exigiram que os profissionais da área contábil a compreender e a apropriar um maior número de informações para garantir aos gestores um retorno com mais agilidade, precisão e fidelidade. Estas necessidades organizacionais, por conseguinte, se repercutiram diretamente na educação (ANTONELLI; COLAUTO; CUNHA, 2011). Portanto, as novas funções e desempenhos esperados do perfil do profissional contábil têm ampliado às exigências na metodologia de formação com a finalidade de desenvolver diversas competências de educação, de relacionamentos, além das classificadas como básicas nos diversos campos de conhecimento.

\subsection{Taxonomia de Bloom}

Em 1956, a Taxonomia dos Objetivos Educacionais foi idealizada a partir de uma reunião de pesquisadores, tendo como líder Benjamin S. Bloom e os colaboradores Engelhart, Furst, Hill e Krathwohl. A pretensão da Associação Norte Americana de Psicologia (American Psychological Association - APA) era organizar uma atividade em conjunto com a finalidade de criar os objetivos de processos educacionais. Em homenagem ao líder da equipe essa Taxonomia passou a ser chamada "Taxonomia de Bloom” (LOMENA, 1999).

Essa Taxonomia é definida como uma ciência da identificação, classificação, denominação e organização utilizada para instituir o conjunto de termos representativos de uma área ou sistema pré-determinado que compartilham características similares e tem como resultante um framework conceitual para discussões, análises e/ou recuperação de informação.

A Taxonomia de Bloom é utilizada na educação, principalmente para incentivar e auxiliar os educadores a usarem uma forma lógica e estruturada, através de uma estratégia diferenciada, com a finalidade de que os discentes dominem habilidades das mais simples para as mais complexas, e dessa forma fazer com que os alunos adquiram as competências específicas (BLOOM,1956). Foi estruturada para promover o diálogo entre educadores e discentes e assim obter o comportamento esperado, fornecendo uma linguagem comum dos objetivos educacionais (ESKRIDGE, 2010).

Apresentam-se três domínios: cognitivo, afetivo e psicomotor. Neste trabalho, o foco envolve exclusivamente o domínio cognitivo, o qual está relacionado ao aprender, dominar um conhecimento, adquirir uma nova informação para o desenvolvimento intelectual.

O domínio cognitivo tem como propósito destacar o que foi aprendido, recordando ou solucionando algum problema, à medida que se conhece certo assunto pode-se compreendê-lo e aplicá-lo, reorganizando ou associando ideais, métodos anteriormente aprendidos. Dessa forma, Bloom e sua equipe construíram uma estrutura dos termos para que obedecesse a uma ordem sequencialmente.

Figura 2 -Estruturação da Taxonomia de Bloom no Domínio Cognitivo

R. Cont. Ufba, Salvador-Ba, v. 7, n. 3, p. 38 - 58, dezembro-março 2014 


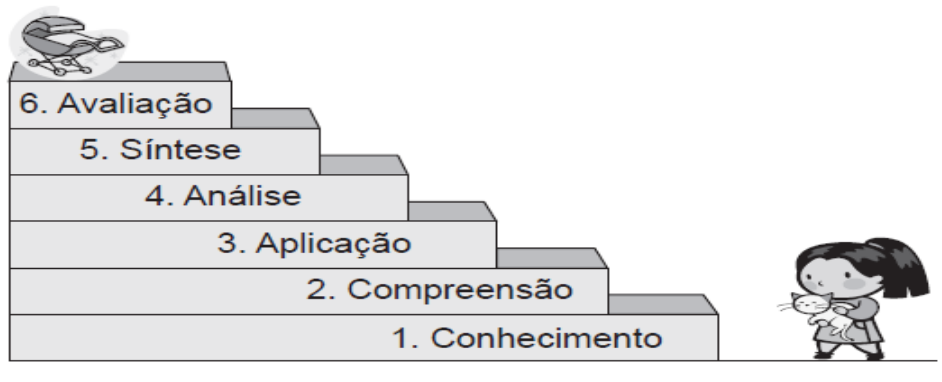

Fonte: Belhot e Ferraz (2010)

Para a ascensão de uma categoria para outra, é necessário ter obtido o desenvolvimento ideal na fase atual, pois cada uma utiliza de habilidades que foram adquiridas nos níveis antecedentes. Nesse domínio, conforme Bloom (1956), os objetivos foram reunidos em seis grupos e são delineados numa camada de complexidade e dependência (categorias), do mais simples ao mais complexo. Bloom (1956) afirma que as categorias de domínio cognitivo são: conhecimento, compreensão, aplicação, análise, síntese e avaliação, conforme ilustrado na Figura 2.

\subsection{Taxonomia Revisada de Bloom}

A Taxonomia de Bloom Original foi utilizada durante quarenta anos, e somente em 1999, Anderson e alguns colaboradores se reuniram formando uma comissão com o objetivo de obter a mesma praticidade de Bloom et al. (1956) e publicou um estudo sobre a retrospectiva da utilização da Taxonomia. A ideia central da Taxonomia buscou apenas um equilíbrio entre o que já existia com as posições atuais de Anderson e sua equipe.

Krathwohl (2002) destacou que geralmente os objetivos declaram o que é esperado que os discentes aprendam, contudo, esquecem de explicitar, de forma coerente, o que eles são capazes de realizar com aquele conhecimento. Observaram que alterações na Taxonomia original eram precisas e o primeiro passo verificado seria à questão do verbo e sua agregação direta com o objetivo cognitivo, avaliação do objetivo e desenvoltura de competências. Os pesquisadores envolvidos chegaram à conclusão de que verbos e substantivos precisariam pertencer a dimensões distintas na qual os substantivos constituiriam a base para a dimensão do conhecimento e verbo para a dimensão pertencente às perspectivas cognitivas.

O Domínio Cognitivo da Taxonomia Revisada de Bloom, como na versão original, é formado por seis categorias, da mais simples à mais complexa, são elas: Lembrar (Conhecimento), Entender (Compreensão), Aplicar (Aplicação), Analisar (Análise), Avaliar (Avaliação) e Criar (Síntese). Anderson et al. (2001) renomearam a categoria "Síntese" como "Criar" e colocaramna, na nova Taxonomia, em uma ordem invertida com a categoria "Avaliação".

\section{Procedimentos Metodológicos}

Foi desenvolvida uma pesquisa com desenho metodológico exploratório e descritivo com abordagem quantitativa. A pesquisa descritiva é utilizada para demonstrar a organização, apresentação e descrição dos dados representativos da amostra. A pesquisa exploratória tem como atributo a necessidade de compreensão e concepção de um problema com maior grau de precisão (MALHOTRA, 2001). Martins e Theóphilo (2007) inferem que a pesquisa quantitativa incide em organizar, sumarizar, caracterizar e interpretar dados numéricos coletados, por meio da aplicação de métodos e técnicas estatísticas. Usa-se uma abordagem quantitativa enquanto investiga os alunos com um instrumento a ser validado. 


\subsection{Participantes}

O estudo para reconhecer se existem diferenças significativas no nível da aprendizagem dos alunos do curso de graduação em Ciências Contábeis que estudam na modalidade presencial e à distância mediante o estágio do estudante no curso foi realizado através da análise de uma amostra formada por discentes das IES das cidades de Senhor do Bonfim e Euclides da Cunha - Bahia, Brasil.

A utilização de uma amostra diversificada possibilitou agregar os respondentes em função da modalidade de ensino e dessa forma agrupar os mesmos em dois níveis distintos, ou seja, EAD e presencial. A coleta de dados ocorreu em maio e junho de 2012. O total de alunos matriculados nas IES analisadas corresponde a 328 alunos. Na aplicação dos questionários, obteve-se a resposta de 264 participantes, sendo que 31 foram expurgados da amostra final em função de apresentarem valores ausentes (missing values). Portanto, a amostra desta pesquisa ficou em 233 questionários válidos, o que representa $71 \%$ do universo amostral.

As estatísticas descritivas da amostra analisada evidenciam-se a partir da Tabela 1. Com base nos dados apresentados, verifica-se a agregação das IES por modalidade, evidenciando a quantidade de respondentes. Dessa forma mostra-se que $48,1 \%$ dos respondentes fazem parte da modalidade EAD e 51,9\% da modalidade presencial, existindo dessa forma um equilíbrio na quantidade dos respondentes por modalidade, oferecendo suporte necessário para a verificação do desempenho, mediante a hierarquia da Taxonomia Revisada de Bloom, entre os alunos destas modalidades de ensino.

Tabela 1 - Composição da amostra por modalidade de ensino

\begin{tabular}{c|c|c}
\hline & Frequência & Percentual \\
\hline Presencial & 112 & 48,1 \\
\hline EAD & 121 & 51,9 \\
\hline Total & 233 & 100,0
\end{tabular}

Fonte: Elaboração própria, 2013.

A Tabela 2 evidencia a existência da dispersão entre a porcentagem do número de respondentes por cada tipo de questionário, ou seja, a equidade na quantidade de respondentes mediante ao estágio que se encontra o estudante no curso. Observa-se que os questionários 1 e 2 possuíram a mesma quantidade de respondentes, já o questionário 3 obteve uma menor porcentagem, isso se justifica porque este instrumento de pesquisa foi destinado aos concluintes e, como na maioria das IES, essas também possui um declínio na quantidade de alunos com o transcorrer dos semestres.

Tabela 2 - Composição da quantidade de respondentes por tipo de questionário.

\begin{tabular}{c|c|c}
\cline { 2 - 3 } & Respondentes & Percentual Válido \\
\hline Instrumento 1 & 84 & 36,1 \\
\hline Instrumento2 & 84 & 36,1 \\
\hline Instrumento3 & 65 & 27,9 \\
\hline Total & 233 & 100,0 \\
\hline
\end{tabular}

Fonte: Elaboração própria, 2013.

Por fim, a Tabela 3 evidencia como está estruturado o número de respondentes por idade. Para realização de comparativos futuros, será utilizada a idade por agrupamento, ou seja, um $1^{\circ}$ grupo abaixo de 25 anos e um $2^{\circ}$ grupo acima de 25 anos, visto que, conforme dados 
apresentados, o grupo $1^{\circ}$ corresponde a $45,5 \%$ dos respondentes e o outro grupo com $54,5 \%$, evidenciando dessa forma um equilíbrio.

Tabela 3 - Composição da amostra por idade agrupada

\begin{tabular}{c|c|c|c|c}
\hline & Frequência & Percentual & $\begin{array}{c}\text { Percentual } \\
\text { Válido }\end{array}$ & $\begin{array}{c}\text { Percentagem } \\
\text { Cumulativa }\end{array}$ \\
\hline Até 20 anos & 30 & 12,9 & 12,9 & 12,9 \\
\hline 21 a 25 anos & 76 & 32,6 & 32,6 & 45,5 \\
\hline 26 a 30 anos & 61 & 26,2 & 26,2 & 71,7 \\
\hline 31 a 35 anos & 30 & 12,9 & 12,9 & 84,5 \\
\hline Acima de 36 anos & 36 & 15,5 & 15,5 & 100,0 \\
\hline Total & 233 & 100,0 & 100,0 & \\
\hline \multicolumn{5}{|c|}{ Fonte: Elaboração Própria, 2013. }
\end{tabular}

\subsection{Instrumento de Pesquisa}

Para poder testar as hipóteses foram desenvolvidos três tipos de questionários compostos por seis questões cada, seguindo a estrutura dos níveis da Taxonomia de Bloom, conforme se verificam nos Apêndices A, B e C. A estrutura dos questionários mediante a hierarquia da Taxonomia Revisada de Bloom tem a intenção de detectar qual o nível de aprendizado que se encontram os respondentes de cada modalidade de ensino. Cada questionário foi direcionado por semestre, questionário 1 foi aplicado nos $1^{\circ}$ e $2^{\circ}$ semestres, questionário 2 nos $3^{\circ}, 4^{\circ}$ e $5^{\circ}$ semestres e questionário 3 aplicado nos $6^{\circ}, 7^{\circ}$ e $8^{\circ}$ semestres. Os três questionários foram elaborados por questões a partir dos dados das propostas para ementas das disciplinas instruídas pelo Conselho Federal de Contabilidade (CFC) conforme o Plano Nacional de Proposta (2008), ou seja, foi verificado o conteúdo indicado para cada disciplina apresentada aos semestres iniciais, intermediários e finais e assim foram construídas as questões para os três questionários. Bloom e sua equipe organizaram verbos os quais são destinados ao reconhecimento de cada nível de aprendizagem, desta forma foram utilizados os verbos para a construção de cada pergunta do questionário, seguindo a estrutura dos seis níveis de aprendizagem, conforme se nota em negrito em cada pergunta do questionário (vide Apêndices).

\subsection{Testes de Hipóteses}

As hipóteses desta pesquisa foram criadas e testadas a partir da realização de um modelo operacional de pesquisa. As variáveis foram "Estágio do Estudante no Curso" e "idade" todas ligadas diretamente ao "nível de aprendizagem", conforme apresentado na Figura 3.

Figura 3 - Modelo Operacional de Pesquisa com hipóteses.

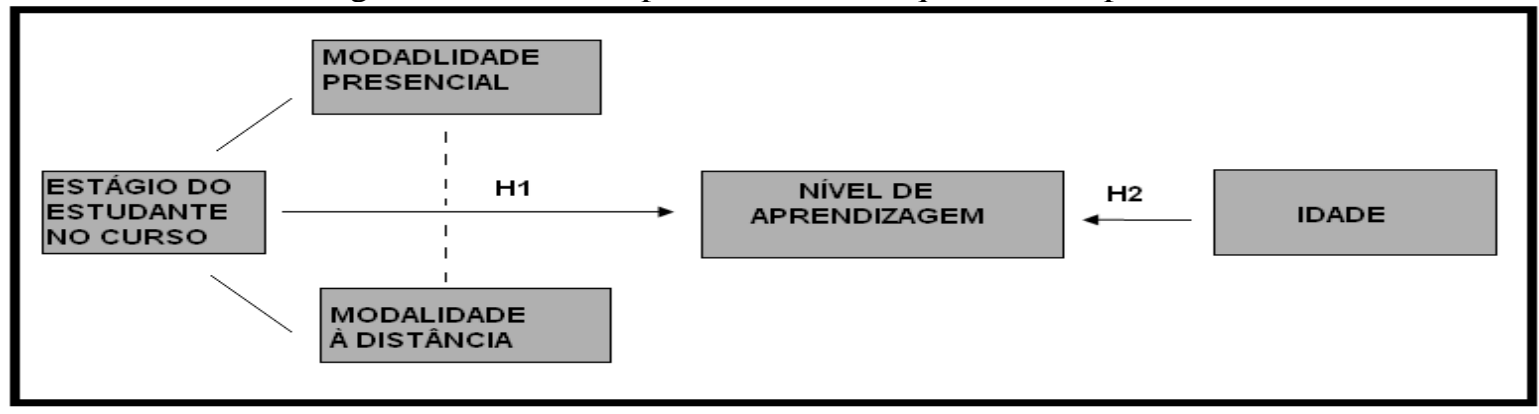

Fonte: Elaboração própria, 2013. 
Com a finalidade de responder ao problema e cumprir os objetivos estabelecidos por esta pesquisa duas hipóteses foram construídas. A primeira hipótese, $\mathrm{H}_{1}$, evidencia que existem diferenças significativas no nível de aprendizagem entre alunos iniciantes, intermediários e concluintes. Esta hipótese encontra suporte nas evidências encontradas por Grundspenkis e Anohina (2009).

A segunda hipótese, $\mathrm{H}_{2}$, se refere a variável "idade" inserida no modelo evidenciando que existem diferenças significativas no nível de aprendizagem entre alunos mais jovens e mais maduros. As evidências encontradas por Lake (2008) fornecem apoio para a construção desta hipótese.

\section{Análise dos Dados}

\subsection{Estatísticas Descritivas}

Inicialmente a análise dos dados deste estudo apresenta-se as estatísticas descritivas da aplicação do instrumento de pesquisa, por meio da interpretação dos dados mediante cada questionário.

A Taxonomia Revisada de Bloom utiliza como requisito uma classificação hierárquica para os objetivos de aprendizagem, esses níveis se dividem em seis categorias: lembrar, entender, aplicar, analisar, avaliar e criar. Para evoluir de um nível para outro é condição imprescindível ter pleno domínio do nível em que se encontra, pois cada grau de competências contém uma descrição útil para categorizar os resultados de aprendizagem, dessa forma o ideal é alcançar a capacidade de criar (GATZEN; PAPE; RUFFERT, 2007).

Tabela 4 - Quantidade de respondentes por níveis de aprendizagem

\begin{tabular}{l|c|c}
\cline { 2 - 3 } & Frequência & Percentual \\
\hline (1) Lembrar & 113 & 48,5 \\
\hline (2) Entender & 35 & 15,0 \\
\hline (4) Anlicar & 45 & 19,3 \\
\hline (5) Avaliar & 13 & 5,6 \\
\hline (6) Criar & 8 & 3,4 \\
\hline Total & 233 & 8,2 \\
\hline
\end{tabular}

Fonte: Elaboração própria, 2013.

A Tabela 4 apresenta a quantidade de respondentes que se encontram em cada nível da Taxonomia de Bloom. A partir desses dados identifica-se que quase a metade dos respondentes se encontram no nível 1 da Taxonomia Revisada de Bloom, ou seja, no nível que corresponde ao "lembrar" e consiste em apenas reconhecer e recordar informações e conteúdos previamente abordados tendo como objetivo principal trazer à consciência os conhecimentos tratados. O que é um quadro alarmante uma vez que o nível máximo de conhecimento evidenciado pela Taxonomia Revisada de Bloom é o estado de criar que se encontra no grau 6 e nesse nível, dos 233 respondentes, apenas 19 conseguiram atender todas as questões e dessa forma atingir este nível, o qual corresponde a somente $8,2 \%$ dos alunos analisados.

Tabela 5 - Comparativo entre os níveis de Taxonomia Revisada de Bloom por estágio do estudante no curso Inicial, Intermediário e Concluinte - das duas modalidades

\begin{tabular}{c|c|c|c|c|c}
\hline \multicolumn{2}{c|}{ Nível Inicial } & \multicolumn{2}{c|}{ Nível Intermediário } & \multicolumn{2}{c}{ Nível Concluinte } \\
\hline Frequência & Percentual & Frequência & Percentual & Frequência & Percentual \\
\hline
\end{tabular}

R. Cont. Ufba, Salvador-Ba, v. 7, n. 3, p. 38 - 58, dezembro-março 2014 


\begin{tabular}{l|c|c|c|c|c|c}
\hline (1) Lembrar & 49 & 59,3 & 36 & 42,9 & 28 & 43,1 \\
\hline (2) Entender & 10 & 11,9 & 12 & 14,3 & 13 & 20,0 \\
\hline (3) Aplicar & 11 & 13,1 & 25 & 29,8 & 9 & 13,8 \\
\hline (4) Analisar & 4 & 4,8 & 3 & 3,6 & 6 & 9,2 \\
\hline (5) Avaliar & 4 & 4,8 & 2 & 2,4 & 2 & 3,1 \\
\hline (6) Criar & 6 & 7,1 & 6 & 7,1 & 7 & 10,8 \\
\hline Total & 84 & 100 & 84 & 100 & 65 & 100 \\
\hline
\end{tabular}

Fonte: Elaboração própria, 2013.

A Tabela 5 constata um comparativo entre os níveis da Taxonomia Revisada de Bloom por estágio do estudante no curso abrangendo os 233 respondentes das duas modalidades de ensino. Verifica-se que no nível inicial uma porcentagem de $84,3 \%$ respondentes se encontra nos três primeiros níveis da Taxonomia, assim como os respondentes do nível intermediário obtiveram $87 \%$ nas mesmas questões e no nível concluinte foi conferida uma porcentagem inferior, de $76,9 \%$.

Analisando a segunda parte do questionário que estão incluídas as questões com maior nível de dificuldade sendo ilustrada na Tabela 5 pelas questões 4, 5 e 6 verifica-se que no nível inicial foi apurada uma porcentagem de $16,7 \%$ de alunos nesses níveis e já no nível concluinte essa situação teve um progresso conferindo uma porcentagem de $23,1 \%$, ou seja, esse desenvolvimento é satisfatório afirmando que com a evolução do estágio dos estudantes no curso é verificado também um desenvolvimento em seu nível de aprendizado.

Tabela 6 - Comparativo entre os níveis de Taxonomia Revisada de Bloom por estágio do estudante no curso Inicial, Intermediário e Concluinte - Modalidade Presencial.

\begin{tabular}{l|c|c|c|c|c|c} 
& \multicolumn{2}{c}{ Nível Inicial } & \multicolumn{2}{c}{ Nível Intermediário } & \multicolumn{2}{c}{ Nível Concluinte } \\
\cline { 2 - 7 } & Frequência & Percentual & Frequência & Percentual & Frequência & Percentual \\
\hline (1) Lembrar & 23 & 69,7 & 13 & 39,4 & 21 & 38,2 \\
\hline (2) Entender & 0 & 0 & 4 & 12,1 & 12 & 21,8 \\
\hline (3) Aplicar & 5 & 15,2 & 8 & 24,2 & 8 & 14,5 \\
\hline (4) Analisar & 1 & 3,0 & 1 & 3,0 & 5 & 9,1 \\
\hline (5) Avaliar & 1 & 3,0 & 2 & 6,1 & 2 & 3,6 \\
\hline (6) Criar & 3 & 9,1 & 5 & 15,2 & 7 & 12,7 \\
\hline Total & 33 & 100 & 33 & 100 & 55 & 100 \\
\hline
\end{tabular}

Fonte: Elaboração própria, 2013.

A partir da Tabela 6 pode-se verificar o nível da Taxonomia por estágio do estudante no curso apenas na modalidade presencial, evidencia-se que assim como no total dos respondentes explicado anteriormente na modalidade presencial a maioria dos respondentes no nível inicial, intermediário e concluinte obtiveram uma maior porcentagem nas três primeiras questões. Assim como, nas questões que correspondem aos níveis mais altos da Taxonomia Revisada de Bloom, ou seja, nos três últimos níveis 4, 5, 6 é demonstrada também uma evolução, uma vez que no nível inicial foi evidenciada uma porcentagem de $15,1 \%$, no nível médio uma porcentagem de $24,3 \%$ e no nível concluinte $25,4 \%$, concluindo que ao ascender do estágio no curso o estudante ascende também o seu nível de aprendizagem.

Tabela 7 - Comparativo entre os níveis de Taxonomia Revisada de Bloom por estágio do estudante no curso Inicial, Intermediário e Concluinte - Modalidade EAD

\begin{tabular}{l|c|c|c|c|c|c}
\cline { 2 - 7 } & \multicolumn{2}{c}{ Nível Inicial } & \multicolumn{2}{c|}{ Nível Intermediário } & \multicolumn{2}{c}{ Nível Concluinte } \\
\cline { 2 - 7 } & Frequência & Percentual & Frequência & Percentual & Frequência & Percentual \\
\hline (1) Lembrar & 26 & 51,0 & 23 & 45,1 & 7 & 70,0 \\
\hline (2) Entender & 10 & 19,6 & 8 & 15,7 & 1 & 10,0 \\
\hline
\end{tabular}

R. Cont. Ufba, Salvador-Ba, v. 7, n. 3, p. 38 - 58, dezembro-março 2014 


\begin{tabular}{l|c|c|c|c|c|c}
\hline (3) Aplicar & 6 & 11,8 & 17 & 33,3 & 1 & 10,0 \\
\hline (4) Analisar & 3 & 5,9 & 2 & 3,9 & 1 & 10,0 \\
\hline (5) Avaliar & 3 & 5,9 & 0 & 0 & 0 & 0 \\
\hline (6) Criar & 3 & 5,9 & 1 & 2,0 & 0 & 0 \\
\hline Total & 51 & 100 & 51 & 100 & 10 & 100 \\
\hline
\end{tabular}

Fonte: Elaboração própria, 2013.

A Tabela 7 evidencia o nível de aprendizagem pelo estágio do estudante no curso com relação a modalidade EAD, mostrando que a maioria dos respondentes possuem um nível de aprendizagem 2, ou seja o nível "Entender", mas, observando a ascensão do estágio inicial ao estágio concluinte, ou seja, o avanço dos semestres, verifica-se um desenvolvimento e este fator é imprescindível. Apesar de ter ocorrido uma clara e evidente evolução, a qual obteve uma porcentagem de $16,59 \%$, este escore poderia ser maior e mais relevante, visto que é esperado quanto maior o estágio do estudante maior deverá ser o seu nível de aprendizado.

Tabela 8 - Nível da Aprendizagem por Estágio do Estudante no Curso

Nível Taxonomia X Estágio do Estudante no Curso

\begin{tabular}{c|c|c|c}
\hline Estágio do Estudante & Média & $\mathrm{N}$ & Desvio Padrão \\
\hline Inicial & 2,0714 & 84 & 1,58141 \\
\hline Intermediário & 2,2976 & 84 & 1,47084 \\
\hline Concluinte & 2,4154 & 65 & 1,67605 \\
\hline Total & & 233 & \\
\hline
\end{tabular}

Fonte: Elaboração própria, 2013.

Tabela 9 - Comparativo dos níveis de aprendizagem por Idade

\begin{tabular}{l|c|c|c|c}
\cline { 2 - 5 } & \multicolumn{2}{c|}{ Abaixo de 25 anos } & \multicolumn{2}{c}{ Acima de 25 anos } \\
\cline { 2 - 5 } & Frequência & Percentual & Frequência & Percentual \\
\hline (1) Lembrar & 45 & 49,5 & 68 & 47,9 \\
\hline (2) Entender & 13 & 14,3 & 22 & 15,5 \\
\hline (3) Aplicar & 17 & 18,7 & 28 & 19,7 \\
\hline (4) Analisar & 3 & 3,3 & 10 & 7,0 \\
\hline (5) Avaliar & 4 & 4,4 & 4 & 2,9 \\
\hline (6) Criar & 9 & 9,8 & 10 & 7,0 \\
\hline Total & 91 & 100 & 142 & 100 \\
\hline
\end{tabular}

Fonte: Elaboração própria, 2013

Com relação à comparabilidade entre o nível de Taxonomia Revisada de Bloom pela idade, agrupa-se primeiramente em dois grupos, abaixo de 25 anos e acima de 25 anos, foi verificado que dentre os 233 respondentes, os respondentes que permaneceram nos três primeiros níveis da Taxonomia com idade abaixo de 25 anos apresentaram uma porcentagem de $82,5 \%$ e acima de 25 anos $83,1 \%$.

A partir dos dados dos níveis mais complexos da Taxonomia constata-se que os respondentes abaixo de 25 anos apresentaram uma porcentagem de $17,5 \%$ e os respondentes acima de 25 anos uma porcentagem de $16,9 \%$, ou seja, mediante os níveis com maior grau de dificuldade evidenciados na Tabela 9 pelas questões 4,5 e 6 os respondentes abaixo de 25 anos possuem um maior nível de aprendizado.

Tabela 10 - Comparativo níveis de aprendizagem por Idade - Modalidade EAD

\begin{tabular}{l|c|c|c|c}
\cline { 2 - 5 } & \multicolumn{2}{c|}{ Abaixo de 25 anos } & \multicolumn{2}{c}{ Acima de 25 anos } \\
\cline { 2 - 5 } & Frequência & Percentual & Frequência & Percentual \\
\hline (1) Lembrar & 16 & 51,6 & 40 & 49,4 \\
\hline (2) Entender & 5 & 16,1 & 14 & 19,3 \\
\hline
\end{tabular}

R. Cont. Ufba, Salvador-Ba, v. 7, n. 3, p. 38 - 58, dezembro-março 2014 


\begin{tabular}{l|c|c|c|c}
\hline (3) Aplicar & 7 & 22,6 & 17 & 21,0 \\
\hline (4) Analisar & 0 & 0 & 6 & 7,3 \\
\hline (5) Avaliar & 1 & 3,2 & 2 & 2,5 \\
\hline (6) Criar & 2 & 6,5 & 2 & 2,5 \\
\hline Total & 31 & 100 & 81 & 100 \\
\hline
\end{tabular}

Fonte: Elaboração própria, 2013.

Observando a comparabilidade nível da Taxonomia de Bloom pela idade apenas na modalidade EAD, demonstrado na Tabela 10, evidencia-se que os respondentes que se encontram nos níveis iniciais da Taxonomia com idade abaixo de 25 anos correspondem a 90,3\% e com idade superior a 25 anos $89,7 \%$ e nos níveis com maior dificuldade constata-se que os respondentes com idade abaixo de 25 anos apresentaram uma porcentagem de 9,7\% e acima de 25 anos $12,3 \%$. Com base nesses dados pode-se afirmar que na modalidade EAD o grupo idade acima de 25 anos possui maior nível de conhecimento.

Tabela 11 - Comparativo níveis de aprendizagem por Idade - Modalidade Presencial

\begin{tabular}{l|c|c|c|c}
\cline { 2 - 5 } & \multicolumn{2}{c|}{ Abaixo de 25 anos } & \multicolumn{2}{c}{ Acima de 25 anos } \\
\cline { 2 - 5 } & Frequência & Percentual & Frequência & Percentual \\
\hline (1) Lembrar & 29 & 48,3 & 28 & 45,9 \\
\hline (2) Entender & 8 & 13,3 & 8 & 13,1 \\
\hline (3) Aplicar & 10 & 16,7 & 11 & 18,0 \\
\hline (4) Analisar & 3 & 5,0 & 4 & 6,6 \\
\hline (5) Avaliar & 3 & 5,0 & 2 & 3,3 \\
\hline (6) Criar & 7 & 11,7 & 8 & 13,1 \\
\hline Total & 60 & 100 & 61 & 100 \\
\hline
\end{tabular}

Fonte: Elaboração própria, 2013.

Por fim, examinando a Tabela 11 e fazendo a mesma comparabilidade realizada anteriormente verifica-se que nos primeiros três níveis da Taxonomia foram preenchidos por 78,3\% pelo grupo idade abaixo de 25 anos e 77\% pelo grupo acima de 24 anos. Observando os níveis de maior complexidade, ou seja, os acertos das questões 4, 5 e 6 foi constado que o grupo idade abaixo de 25 anos obteve uma porcentagem de $21,7 \%$ e acima de 25 anos uma porcentagem de $23 \%$, ou seja, o grupo acima de 25 anos possuem um maior nível de aprendizado mediante os critérios propostos pela Taxonomia Revisada de Bloom.

\subsection{Validação dos Instrumentos de Pesquisa}

Pesquisas de natureza exploratória e quantitativa, naturalmente são colocadas em dúvida devido à confiabilidade dos instrumentos de coleta. Quando se produz um questionário para constatar a percepção de pessoas sobre uma determinada problemática o que se quer na verdade é que as medições reflitam os verdadeiros resultados do questionário e estejam livres de erros aleatórios (ROSENBERG, 2002). Dessa forma, apresenta-se abaixo a validação de cada instrumento utilizado para esta pesquisa.

A validação dos três instrumentos de pesquisa pode ser verificada na Tabela 12, a qual revela os testes da Matriz anti-imagem e Comunalidade evidenciando que todos os valores obtidos foram acima de 50\%. Para o teste de Variância Total Explicada a qual verifica o número mínimo de fatores que respondem pela máxima variância mostra-se que os dois primeiros componentes dos instrumentos somam-se a variância total dos indicadores. Evidencia-se também que o teste de KMO foi considerado aceitável nos três instrumentos, bem como o Alfa de Cronbach apontando valores acima de 0,60 . Também foi possível perceber o baixo nível de significância 
desejável para o teste de esfericidade de Bartlett, concluindo que os três instrumentos de pesquisas foram validados.

Tabela 12 - Validação dos Instrumentos de Pesquisa

\begin{tabular}{|c|c|c|c|c|}
\hline \multicolumn{5}{|c|}{ Passos associados à validação dos três instrumentos de pesquisa } \\
\hline & Regras para validação & Instrumento 1 & Instrumento 2 & Instrumento 3 \\
\hline $\begin{array}{l}\text { Matrizes Anti- } \\
\text { imagem }\end{array}$ & $\begin{array}{c}\text { Medida da adequação } \\
\text { amostral de cada variável. } \\
\text { Valores }>50 \%\end{array}$ & $>50 \%$ & $>50 \%$ & $>50 \%$ \\
\hline Comunalidade & $\begin{array}{c}\text { Evidencia a proporção da } \\
\text { variância de cada variável } \\
\text { explicada pelos } \\
\text { componentes principais. } \\
\text { Valores }>50 \%\end{array}$ & $>50 \%$ & $>50 \%$ & $>50 \%$ \\
\hline $\begin{array}{c}\text { Variância total } \\
\text { explicada }\end{array}$ & $\begin{array}{l}\text { Número mínimo de fatores } \\
\text { que respondem pela } \\
\text { máxima variância }\end{array}$ & $\begin{array}{l}\text { Componentes } 1 \\
\text { e } 2 \text { somam-se } \\
57,135 \% \text { da } \\
\text { variância total } \\
\text { dos indicadores. }\end{array}$ & $\begin{array}{c}\text { Componentes } 1 \\
\text { e } 2 \text { somam-se } \\
53,471 \% \text { da } \\
\text { variância total } \\
\text { dos indicadores. }\end{array}$ & $\begin{array}{c}\text { Componentes } 1 \\
\text { e } 2 \text { somam-se } \\
46,498 \% \text { da } \\
\text { variância total } \\
\text { dos indicadores. }\end{array}$ \\
\hline \multicolumn{5}{|c|}{ Dimensionalidade } \\
\hline . KMO & $\begin{array}{l}\text { Maior que 0,7: Desejável } \\
\text { Entre 0,5 e 0,69: Aceitável } \\
\text { Menor que 0,5: Indesejável }\end{array}$ & $\begin{array}{c}0,642 \\
\text { Aceitável }\end{array}$ & $\begin{array}{c}0,559 \\
\text { Aceitável }\end{array}$ & $\begin{array}{c}0,629 \\
\text { Aceitável }\end{array}$ \\
\hline $\begin{array}{l}\text { Teste de } \\
\text { esfericidade } \\
\text { De Bartlett. }\end{array}$ & Significância < 5\% & $\begin{array}{c}\text { Nível de } \\
\text { significância } \\
\text { igual a } 0,000 .\end{array}$ & $\begin{array}{c}\text { Nível de } \\
\text { significância } \\
\text { igual a } 0,000 .\end{array}$ & $\begin{array}{l}\text { Nível de } \\
\text { significância } \\
\text { igual a } 0,001 .\end{array}$ \\
\hline \multicolumn{5}{|l|}{ Confiabilidade } \\
\hline $\begin{array}{c}\text { Alfa de } \\
\text { Cronbach }\end{array}$ & Alpha de Cronbach> 0,60 & 0,671 & 0,600 & 0,603 \\
\hline
\end{tabular}

Fonte: Elaboração própria, 2013.

\subsection{Normalidade}

O teste de normalidade é indicado para que se possa selecionar o tratamento mais adequado para o teste de hipótese. Como afirma Lima Filho (2010) a utilização dos dados de Kolmogorov e não de Shapiro se justifica mediante a amostra, ou seja, se a amostra é superior a vinte utilizase Kolmogorov e inferior a 20 estabelece Shapiro, dessa forma, a composição da amostra foi de 233 respondentes submetendo-se ao teste Kolmogorov-Smirnov.

Tabela 13 - Teste de Normalidade

\begin{tabular}{c|c|c|c|c|c|c} 
& \multicolumn{2}{c}{ Kolmogorov-Smirnov $^{\mathbf{a}}$} & \multicolumn{3}{c}{ Shapiro-Wilk } \\
\cline { 2 - 7 } & Estatística & Df & Sig. & Statistic & df & Sig. \\
\hline Tipo de questionário &, 236 & 233 &, 000 &, 797 & 233 &, 000 \\
\hline Nível de Taxonomia &, 272 & 233 &, 000 &, 771 & 233 &, 000 \\
\hline Idade Agrupada &, 397 & 233 &, 000 &, 619 & 233 &, 000 \\
\hline
\end{tabular}

Fonte: Elaboração própria, 2013.

Se a amostra se apresenta com normalidade o tratamento deve ser paramétrico. Mas, os dados desta amostra tem a propensão de não serem normais conforme se verifica na Tabela 13, o nível significância de $0 \%$ em todas as variáveis conduz a rejeição da hipótese nula de normalidade. Portanto, adota-se testes não-paramétricos para o teste de hipóteses deste estudo.

\subsection{Homogeneidade}




\subsubsection{Teste de Homogeneidade das Hipóteses}

Tabela 14 - Teste de homogeneidade da Variância

\begin{tabular}{c|c|c|c|c|c|c}
\hline \multicolumn{2}{l|}{} & $\begin{array}{c}\text { Levene } \\
\text { Estatística }\end{array}$ & df1 & df2 & Sig. \\
\hline $\begin{array}{c}\text { Teste de } \\
\text { Homogeneidade da } \\
\text { Variância - Hipótese 1 }\end{array}$ & Tipo de questionário & Com base na média & 2,514 & 5 & 227 &, 031 \\
\hline $\begin{array}{c}\text { Teste de } \\
\text { Homogeneidade da } \\
\text { Variância - Hipótese 2 }\end{array}$ & Idade & Com base na média & 3,118 & 5 & 227 &, 010 \\
\hline
\end{tabular}

Fonte: Elaboração própria, 2013.

O teste de homogeneidade da hipótese 1, constatou que o grau de significância baseado na média das variâncias foi de 0,031 , portanto, $3,1 \%$, logo, está dentro do alfa de $5 \%$. Neste caso, a hipótese nula $\mathrm{H}_{0}$ foi rejeitada porque as variâncias são diferentes.

No teste de homogeneidade da hipótese 2, o grau de significância baseado na média das variâncias foi de 0,010 , portanto, $1 \%$, logo, como na hipótese anterior, está dentro do alfa de $5 \%$. Neste caso, a hipótese nula $\mathrm{H}_{0}$ foi rejeitada porque as variâncias são diferentes.

Dessa forma, não podem ser utilizados testes paramétricos, pois são heterocedásticos (variâncias diferentes entre as amostras), corroborando desta forma, com o resultado do teste de normalidade.

\subsection{Resultados dos Testes de Hipóteses}

\subsubsection{Teste de Hipótese 1 - Nível Aprendizagem X Estágio do estudante no curso}

Para o teste da hipótese $\mathrm{H}_{1}$, foi empregado o teste do qui-quadrado, o qual tem como interpretação que seu nível de significância deve ser baixo o suficiente (inferior a 5\%) para rejeitar a hipótese nula.

Apresenta-se como hipóteses:

$\mathrm{H}_{10}$ - Não Existem diferenças significativas no nível de aprendizagem entre alunos iniciantes, intermediários e concluintes.

$\mathrm{H}_{11}$ - Existem diferenças significativas no nível de aprendizagem entre alunos iniciantes, intermediários e concluintes.

Tabela 15 - Teste Qui- quadrado - Hipótese 1

\begin{tabular}{lllll}
\hline & Hipótese Nula & Teste & Significância & Decisão \\
\hline 1 & $\begin{array}{l}\text { As categorias do Nível } \\
\text { da Taxonomia ocorrer } \\
\text { com possibilidades } \\
\text { iguais }\end{array}$ & & ,000 & Rejeita a hipótese \\
nula
\end{tabular}

Fonte: Elaboração própria, 2013.

Os resultados apontam para diferenças significativas desde que a significância seja maior ou igual a 0,05 ( $\mathrm{sig}$. $\geq 0,05)$, assim, aceita a hipótese nula $\left(\mathrm{H}_{0}\right)$ de igualdade e inexistência de diferenças significativas. Por outro lado, caso a significância obtida aponte um resultado menor que $0,05(\mathrm{Sig}<0,05)$ se aceita a hipótese alternativa $\left(\mathrm{H}_{1}\right)$, de desigualdade e existência de diferenças significativas (BRUNI, 2009). Dessa forma, conforme os resultados obtidos na 
Tabela 15, verifica-se o valor de significância igual a 0,000, ou seja, rejeita-se a hipótese nula $\mathrm{H}_{10}$.

Portanto, existem diferenças significativas nas médias do nível de aprendizagem entre alunos iniciantes, intermediários e concluintes.

Conforme foi evidenciado na Tabela 8 , a partir da análise descritiva, a qual mostra a média do nível de aprendizagem por cada estágio do estudante, obtendo o nível inicial 2,0714, o intermediário 2,2976 e por fim, o nível concluinte com 2,4154, comprovando a evolução das médias dos alunos de acordo com o avanço dos semestres. Este resultado se alinha aos achados de Grundspenkis e Anohina (2009).

\subsubsection{Teste de Hipótese 2 - Nível Aprendizagem X Idade}

$\mathrm{O}$ mesmo tratamento foi aplicado para a $\mathrm{H}_{2}$. Apresenta-se a seguir a hipótese nula e a alternativa:

$\mathrm{H}_{20}$ - Não Existem diferenças significativas no nível de aprendizagem entre alunos mais jovens e mais maduros.

$\mathrm{H}_{21}$ - Existem diferenças significativas no nível de aprendizagem entre alunos mais jovens e mais maduros.

Tabela 16 - Teste qui-quadrado - Hipótese 2

\begin{tabular}{lllll}
\hline & Hipótese Nula & Teste & Significância & Decisão \\
\hline 1 & $\begin{array}{l}\text { As categorias do } \\
\text { Nível } \\
\begin{array}{l}\text { Taxonomia da } \\
\text { ocorrer } \\
\text { possibilidades com } \\
\text { iguais }\end{array}\end{array}$ & $\begin{array}{l}\text { Rejeita a hipótese } \\
\text { nula }\end{array}$ \\
\hline & & & \\
\hline
\end{tabular}

A partir dos resultados apresentados na Tabela 16 conclui-se que a hipótese $\mathrm{H}_{20}$, ou seja, a hipótese nula, também foi rejeitada e com isso evidencia-se que existem diferenças significativas no nível de aprendizagem entre alunos mais jovens e mais maduros, evidenciando que os alunos com idade superior a 25 anos possuem maior nível de aprendizagem, sendo este resultado amparado pela pesquisa de Lake (2008).

\section{Considerações Finais}

A partir da análise de um instrumento próprio de pesquisa, elaborado conforme o Plano Nacional de Proposta instruído pelo CFC (2008) e aplicado numa amostra de 233 estudantes de graduação em Ciências Contábeis de três IES, buscou-se: (a) analisar o nível de aprendizagem dos discentes, através do estágio que os estudantes se encontram no curso nas modalidades de ensino EAD e presencial utilizando os pressupostos da Taxonomia Revisada de Bloom; e (b) se o desempenho dos alunos investigados é alterado mediante variável idade.

Assim, para responder ao problema proposto por esta pesquisa foi realizada aplicação dos questionários, os quais foram interpretados por meio dos testes empíricos e dessa forma permitiram verificar que foram constatadas diferenças significativas entre os níveis de aprendizado dos alunos da modalidade de ensino presencial e à distância, mediante o estágio do estudante do curso, ou seja, inicial, intermediário e concluinte, sendo que os alunos na 
modalidade presencial apresentaram melhor rendimento em relação aos alunos da modalidade EAD.

Com base nisso, o nível de aprendizagem dos estudantes do curso de Ciências Contábeis das IES presenciais e à distância, a partir da hierarquia da Taxonomia Revisada de Bloom, permite afirmar, pelo menos na conjuntura analisada, ou seja, dos alunos das três IES examinadas dos municípios de Euclides da Cunha e Senhor do Bonfim, que o ensino presencial promove aos seus discentes um melhor nível de domínio cognitivo, através do avanço do estágio do estudante no curso corroborando assim, que o objetivo geral desta pesquisa foi atendido. Como também o objetivo específico, evidenciando que com relação à idade, os estudantes mais maduros possuem maior nível de aprendizado.

Esses resultados contribuem de forma significativa com informações para os futuros ingressos na área da Contabilidade, como também para as IES, em especial na localidade analisada, uma vez que identifica como se apresenta o nível de aprendizado nestas instituições de ensino, através da hierarquia da Taxonomia Revisada de Bloom, assim como o modelo de avaliação e análise proposto por esta pesquisa, o qual poderá ser utilizado em outros estudos.

Algumas limitações merecem atenção: evidencia-se que foi utilizada como amostra, alunos de apenas três IES situadas em duas cidades no interior da Bahia, Brasil, esta pesquisa poderia ter uma maior abrangência, contudo, por motivos operacionais, a amostra foi delimitada. Seria interessante também realizar um comparativo mediante os valores do CPC (Conceito Preliminar de Curso), ENADE (Exame Nacional de Desempenho de Estudantes) e SINAES (Sistema Nacional de Avaliação da Educação Superior), das modalidades de ensino analisadas, porém, para que a pesquisa não ficasse muito extensa, não foi exequível.

Novos estudos poderiam ser realizados utilizando o instrumento elaborado nesta pesquisa, podendo ser aplicado somente na área de Contabilidade, com a finalidade de examinar se encontrariam resultados análogos ou divergentes, como também, a replicação da metodologia proposta, desde que o instrumento seja adequado com o contex to do curso analisado.

\section{REFERÊNCIAS}

ANDERSON, L. W. et al. A taxonomy for learning, teaching and assessing: a revison of Bloom's Taxonomy of Educational Objectives. Nova York: Addison Wesley Longman, 2001.

ANDRADE, C. S. O ensino de Contabilidade introdutória nas universidades públicas. São Paulo, 2002. Dissertação (Mestrado em Contabilidade). Departamento de Contabilidade e Atuária, Faculdade de Economia, Administração e Contabilidade da Universidade de São Paulo.

ANTONELLI, R. A.; COLAUTO, R. D.; CUNHA, J. V. A. Expectativa e satisfação dos alunos de Ciências Contábeis com relação às competências docentes. Revista

Iberoamericana sobre Calidad, Eficacia y Cambio en Educación. 10, n 1, 2012.

BELHOT, R.; FERRAZ, A. P. Taxonomia de Bloom: revisão teórica e apresentação das adequações do instrumento para definição de objetivos instrucionais.Gest. \& Prod., v. 17, n. 2, p. 421-431, 2010.

BLOOM, B. (Ed.).Taxonomy of educational objectives: The classification of educational goals: Handbook I, cognitive domain. New York, Toronto: Longas, Green, 1956. 
BRUNI, A. L. SPSS aplicado à pesquisa acadêmica. São Paulo: Atlas, 2009.

CARNEIRO, J. D. et al. Proposta nacional de conteúdo para o curso de graduação em Ciências Contábeis. Brasília: Fundação Brasileira de Contabilidade, 2008.

CORNACHIONE JUNIOR, E. B. Tecnologia da educação e cursos de Ciências Contábeis: modelos colaborativos virtuais. São Paulo, 2004. Tese (Livre Docência em Controladoria e Contabilidade) - Programa de Pós-Graduação em Controladoria e Contabilidade, Departamento de Contabilidade e Atuária, Faculdade de Economia, Administração e Contabilidade da Universidade de São Paulo.

ESKRIDGE, L. Teaching soil conservation in an introductory soil science laboratory and the classification of examinations using the revised bloom's taxonomy. Oklahoma State University Stillwater - OK, 2010.

GATZEN, H. H.; RUFFERT, C.; PAPE, F. Professional Improvement by Study in Engineering Sciences. Institute for Microtechnology, Center for Production Technology, Leibniz Universities Hannover, An der Universities 2, Garbsen, Germany.

GRUNDSPENKIS, J.; ANOHINA, A. Evolution of the concept map based adaptive knowledge assessment system: Implementation and evaluation results. Scientific Proceedings of Riga Technical University, v. 38, n. 5, p. 13-24, 2009.

KRATHWOHL, D. R. A revision of Bloom's taxonomy: an overview. Theory in Practice, v. 41, n. 4, p. 212-218, 2002.

LAKE, M. M. Examining the effects of a community college mathematics teacher and curriculum reformation program: An application of action research and conceptual change. 412f. Dissertação (Mestrado em Educação Matemática). Florida Institute of Technology, 2008.

LIMA FILHO, R. N. Quanto Mais Faço, Mais Erro? Um Estudo Entre a Associação Entre Prática de Controladoria, Cognição e Heurísticas. 159 f. Dissertação (Mestrado em Contabilidade). Programa de Pós-Graduação em Contabilidade, Universidade Federal da Bahia , 2010.

LOMENA, M. Benjamin Bloom. (1999). Disponível em: <http://www.everything2. com/index.pl?node_id=143987>. Acesso em: 20 de maio de 2012.

LOPES, J. E.; PEREIRA, D.; SANTANA JR, Jorge José. Análise das habilidades cognitivas requeridas dos candidatos ao cargo de contador na administração pública federal, utilizandose indicadores fundamentados na visão da Taxonomia de Bloom. Revista Contabilidade e Finanças. - USP - São Paulo, v. 19, n. 46, p. 108 - 121; janeiro/abril, 2008.

MALHOTRA, N. K. Pesquisa de marketing: uma orientação aplicada. 3. .ed. Porto Alegre: Bookman, 2001. 
MARTINS, G. A. e THEÓPHILO, C. R. Metodologia da Investigação Científica para

Ciências Sociais Aplicadas. São Paulo: Ed. Atlas, 2007.

PELEIAS, I. R.; SEGRETI, J. B. SILVA, G. P.; CHIROTTO, A. R. Evolução Do Ensino Da

Contabilidade No Brasil: Uma Análise Histórica. CAP Accounting and Amangement, v. 1, n. 1, 2007.

REIS, A. J. SILVA, S. L. A História Da Contabilidade No Brasil. Seminário Estudantil de Produção Acadêmica - SEPA: Unifacs, v. 11, n. 1, 2007.

RORTY, R.A filosofia e o espírito da natureza. Lisboa: Publicações Dom Quixote. 1988

ROSENBERG, M.J. E-learning: estratégia para a transmissão do conhecimento na era digital. São Paulo: Makron Brooks, 2002.

SILVA, D. M. O Impacto dos Estilos de Aprendizagem no ensino de Contabilidade na FEA - RP. Ribeirão Preto, 2006. Dissertação (Mestrado em Contabilidade) - Faculdade de Economia, Administração e Contabilidade de Ribeirão Preto/USP, 2006.

VEERAVAGU, J.; MUTHUSAMY, C.; MARIMUTHU, R.; MICHAEL, A. S. Using Bloom's Taxonomy to Gauge Students' Reading Comprehension Performance. Canadian Social Science. v. 6, n. 3, p. 205-212, 2010. 


\title{
APÊNDICE A - Instrumento de Pesquisa 1
}

\author{
1) Liste as contas cujos saldos no Balanço Patrimonial são devedores: \\ A) Capital Social Subscrito e ICMS a Recolher. \\ B) Fornecedores e Honorários a Pagar. \\ C) Duplicatas a Receber e Móveis e Utensílios. (X) \\ D) Lucros Acumulados e Contas a Pagar \\ E) Não sei opinar.
}

2) Identifique a qual conta está vinculada a afirmativa.

O valor estabelecido como representativo da parcela de participação do sócio na empresa, mas ainda não entregue em dinheiro.

A) Capital Social.

B) Capital Social Autorizado.

C) Capital Social Vinculado.

D) Capital Social a Integralizar. (X)

E) Não sei opinar.

3) A partir dos dados do Balancete levantado em 31/12/2011.

Receita de Serviços --- R $\$ 1.400,00$

Despesas de Salários --- R $\$ 200,00$

Despesas de Impostos --- R $\$ 200,00$

Despesas de material para Escritório --- R \$200,00

Despesas de energia --- R $\$ 100,00$

Despesas Diversas --- R $\$ 300,00$

Receitas Financeiras --- R\$100,00

Descontos Concedidos --- R $\$ 100,00$

Aplique os valores acima calculando o encerramento das contas de Receita e Despesa e apure o resultado obtido da empresa:

A) $\mathrm{R} \$ 100,00$ de lucro líquido.

B) $\$$ 300,00 de lucro líquido.

C) $\mathrm{R} \$ 400,00$ de lucro líquido. (X)

D) $\mathrm{R} \$ 100,00$ de prejuízo.

E) Não sei opinar.

\section{4) Examine a situação abaixo:}

Em 01.07.11 a Cia. Obama, emitindo nota promissória para 01.07.12 no valor total da operação, tomou um empréstimo no valor líquido de $\mathrm{R} \$$ $12.000,00$ sobre os quais foram cobrados juros simples de $6 \%$ a.a.

A partir dessa informação aponte a alternativa incorreta:

A) em 31.12.11 os juros da operação a serem apropriados ao resultado são de R \$ 360,00;

B) todos os juros antecipados devem ser reconhecidos como incorridos no vencimento; $(\mathrm{X})$

C) o valor nominal da nota promissória emitida pela Cia. Obama é de R\$ 12.720,00;

D) em 01.07 .12 os juros da operação no resultado são de $R \$ 360,00$;

E) Não sei opinar.

5) Considerando as contas abaixo:

I - Empréstimos Auferidos II - Exaustão III- Adiantamento de Clientes

Julgue a afirmativa correta:

(A) I é uma conta de passivo. (X)

(B) I e III são contas de ativo.

(C) II é uma conta de passivo.

(D) II e III são contas do passivo.

(E) Não sei opinar

6) A partir das transações abaixo elabore a ficha de estoque pelo método PEPS/FIFO e responda a alternativa correta.

Estoque Inicial de Mercadorias - 10unid. a $\mathrm{R} \$ 1.000,00$ cada $=$ $\mathrm{R} \$ 10.000,00$

$10-02$ - Venda de seis unidades por $\$ 8.000$

11-02 - Compra de quatro unidades a $\$ 1.500$, cada.

14-02 - Venda de seis unidades por $\$ 8.500$,

A) $\mathrm{O}$ saldo do estoque em 10 de fevereiro era de $\mathrm{R} \$ 6.000,00$

B) O saldo do estoque em 14 de fevereiro era de $\mathrm{R} \$ 3.000,00$ (X)

C) O valor do Custo da Mercadoria Vendida foi de $\mathrm{R} \$ 15.000,00$

D) A quantidade final das mercadorias foram 04 unidades.

E) Não sei opinar. 
APÊNDICE B - Instrumento de Pesquisa 2

1) Liste as principais funções da Contabilidade, em ordem:

A) Registrar, analisar, fiscalizar e ordenar;

B) Analisar, registrar, acompanhar, fiscalizar e demonstrar;

C) Registrar, ordenar, demonstrar, analisar e acompanhar; (X)

D) Fiscalizar, ordenar, registrar, acompanhar e demonstrar;

E) Não sei opinar.

2) Identifique a partir da movimentação abaixo qual o fato administrativo:

C - CaixaD - Obrigações tributárias

A) Fato Permutativo (X)

B) Fato Composto

C) Fato Modificativo

D) Fato Modificativo aumentativo

E) Não sei opinar.

3) A partir dos dados abaixo aplique o somatório nas contas que pertencem ao Ativo e nas contas que pertencem ao Passivo e marque a alternativa correta:

Veículo ----R \$30.000,00

Fornecedores ---- R\$12.000,00

Banco ---- R $\$ 50.000,00$

Estoque ---- R $\$ 28.000,00$

Financiamento ---- R $\$ 13.000,00$

Empréstimo ---- R $\$ 20.000,00$

A) O Ativo possui saldo de $R \$ 128.000,00$

B) O Ativo possui saldo de $R \$ 100.000,00$

C) O Passivo possui saldo de $\mathrm{R} \$ 45.000,00(\mathrm{X})$

D) O Passivo possui saldo de $\mathrm{R} \$ 90.000,00$

E) Não sei opinar.

4) Examine as afirmativas abaixo:

I. As depreciações contábeis são possíveis para todos os bens do ativo imobilizado.

II. As taxas lineares de depreciação aumentam proporcionalmente à vida útil do bem.

III. Valor contábil é o mesmo que valor residual.

IV. A depreciação acumulada reflete o total das despesas com depreciação do bem.

V. Bens depreciados pelo método da soma dos tempos nunca terão valor contábil nulo.

A quantidade de afirmativas incorretasé:

A) 2

B) 3

C) $4(\mathrm{X})$

D) 5

E) Não sei opinar.

5) Sabe-se que a equação patrimonial é expressada por: (PL= A-P). A partir dessa informação avalie qual a situação abaixo que se tem um passivo a descoberto:

A) $\mathrm{A}>\mathrm{P}$

B) $P>A(X)$

C) $P=A$

D) $\mathrm{PL}=\mathrm{A}$

E) Não sei opinar.

6) Um empresa obteve em um determinado mês as seguintes transações:

- Compra de um veículo R $\$ 25.000,00$ à vista;

- Pagamento de Fornecedores $\mathrm{R} \$ 10.000,00$;

- Recebimento de clientes R $\$ 8.000,00$

Afirma-se que a empresa tinha em caixa $\mathrm{R} \$ 80.000,00$, uma dívida registrada na conta Fornecedor no valor de $\mathrm{R} \$ 90.000,00$ e na conta clientes um valor de $\mathrm{R} \$ 10.000,00$. Organize e elabore o novo balancete dessa empresa e marque a alternativa correta.

A) A conta Fornecedor teve seu saldo zerado;

B) A conta Caixa teve um saldo de $\mathrm{R} \$ 53.000,00$ (X)

C) A conta Clientes teve um saldo de $\mathrm{R} \$ 4.000,00$

D) O valor do Ativo no balancete é de $\mathrm{R} \$ 90.000,00$

E) Não sei opinar. 
APÊNDICE C - Instrumento de Pesquisa3

1) Liste de acordo com as Normas Internacionais de Contabilidade (IASB), quais contas são do grupos do Balanço Patrimonial:

A) Ativo Circulante, Realizável à Longo Prazo, Ativo Diferido, Ativo Imobilizado e Exigível à Longo Prazo.

B) Ativo Imobilizado, Ativo Intangível, Exigível à longo prazo e Investimento.

C) Realizável à Longo Prazo, Diferido, Investimentos, Passivo Circulante e Passivo Não Circulante.

D) Ativo Circulante, Passivo Circulante, Patrimônio Líquido, Ativo Circulante, Imobilizado, Intangível e Investimentos. (X)

E) Não sei opinar.

2) A partir da afirmativa abaixo identifique o princípio contábil que determina o registro das variações patrimoniais, desde que tecnicamente estimável, devendo ser realizado mesmo na hipótese de somente existir razoável certeza de sua ocorrência:

A) Continuidade

B) Exclusividade

C) Oportunidade (X)

D) Prudência

E) Não sei opinar.

3) A Empresa Pindaíba S.A, fabricante de calçados, alienou parte de suas máquinas, para substituí-las por máquinas mais modernas. A empresa apresentou os seguintes valores para a negociação:

Máquinas e Equipamentos R $\$ 100.000,00$

Depreciação R \$ 80.000,00

Valor da Venda R $\$ 28.000,00$

Aplique os valores acima e reconheça o lançamento contábil.

A) outras receitas no valor de $\mathrm{R} \$ 8.000,00$. (X)

B) uma despesa não operacional de $\mathrm{R} \$ 18.000,00$.

C) outras despesas no valor de $\mathrm{R} \$ 20.000,00$.

D) um resultado não operacional de $\mathrm{R} \$ 28.000,00$.

E) Não sei opinar.

4) No registro de uma venda de produtos, no valor de $R \$ 1$ milhão, em que $60 \%$ do total serão efetivamente pagos pelo cliente em 60 dias. Examine esse cenário e aponte a alternativa adequada:

A) aumento líquido de $\mathrm{R} \$ 400$ mil no total do ativo.

B) reconhecimento de uma receita no valor de $\mathrm{R} \$ 400 \mathrm{mil}$.

C) crédito em conta do ativo no valor de $\mathrm{R} \$ 600$ mil.

D) aumento da situação líquida da entidade no valor de $\mathrm{R} \$ 1$ milhão. $(\mathrm{X})$

E) Não sei opinar

5) Com base nos dados apresentados da Empresa Pindaíba S.A

Disponível: R\$ 150.000,00 Passivo Circulante: R \$ 120.000,00

Lucro Líquido: $\mathrm{R} \$ 250.000,00$ Estoque: $\mathrm{R} \$ 123.000,00$

a) Calcule o Índice de Liquidez Imediata:

$\mathrm{D} / \mathrm{PC}=150.000 / 120.000=1,25$

b) A partir do Índice obtido julgue a situação em que a empresa se encontra: ( ) Solvente $(\mathrm{X})($ ) Insolvente( ) Não sei opinar.

6) Considere os seguintes dados abaixo, elabore o balanço orçamentário e com base nos dados levantados responda a alternativa correta.

\begin{tabular}{ll} 
Receita corrente prevista & $\mathrm{R} \$ 100.000,00$ \\
Receita de capital prevista & $\mathrm{R} \$ 50.000,00$ \\
Despesa corrente fixada & $\mathrm{R} \$ 100.000,00$ \\
Despesa de capital fixada & $\mathrm{R} \$ 50.000,00$ \\
Receita corrente realizada & $\mathrm{R} \$ 120.000,00$ \\
Receita de capital realizada & $\mathrm{R} \$ 40.000,00$ \\
Despesa corrente realizada & $\mathrm{R} \$ \mathbf{9 0 . 0 0 0 , 0 0}$ \\
Despesa de capital realizada & $\mathrm{R} \$ 50.000,00$ \\
\hline
\end{tabular}

A) Houve um déficit do orçamento corrente de $\mathrm{R} \$ 20.000,00$. (X)

B) Houve um déficit do orçamento de capital de $\mathrm{R} \$ 10.000,00$.

C) Houve um superávit do orçamento corrente de $R \$ 30.000,00$

D) Houve um superávit orçamentário de $\mathrm{R} \$ 40.000,00$

E) Não sei opinar. 